\title{
Award of the 2009 Chromosome Research Prize
}

We are pleased to announce the award of the 2009 Chromosome Research Scholarly Manuscript Prize to Beatrice Weber of the Institute of Botany at Dresden University of Technology. The winning paper is entitled: Nested Ty3-gypsy retrotransposons of a single Beta procumbens centromere contain a putative chromodomain.

It can be found in Chromosome Research volume 17, issue 3, pages 379-396.

Beatrice studied Ecotrophology at the Anhalt University of Applied Sciences (Bernburg, Germany). She carried out a research project on the generation and characterization of transgenic carrots at the Federal Centre for Breeding Research on Cultivated Plants, Quedlinburg, for which she received her diploma. She later joined the Plant Molecular Cytogenetics Group in the Institute of Crop Science and Plant Breeding, Christian Albrechts University of Kiel where she worked under the supervision of Thomas Schmidt. As a member of a BioFuture group funded by the Federal Ministry of Education and Research, her research was focused on the centromeric region as a major functional domain of eukaryotic chromosomes, especially on the analysis of the long-range organization of centromeric LTR retrotransposons in sugar beet (Beta vulgaris). This work was financially supported by a fellowship of the FAZIT foundation.

She currently holds a post-doctoral position in the lab of Thomas Schmidt in the Institute of Botany at Dresden University of Technology. Her work is focused on the investigation of the activity and evolution of LTR retrotransposons and the identification and analysis of two LTR retrotransposons of B. vulgaris belonging to different families of the Ty1-copia group. Part of this work was recently published in Chromosome Research (DOI: 10.1007/ s10577-009-9104-4). The future work will focus on the mechanism involved in the targeted integration of LTR retrotransposons, particularly with regard to centromeric retrotransposons.

The Editorial Board and the publisher of Chromosome Research offer Beatrice their warmest congratulations and wish her every success in her future career as an experimental biologist.

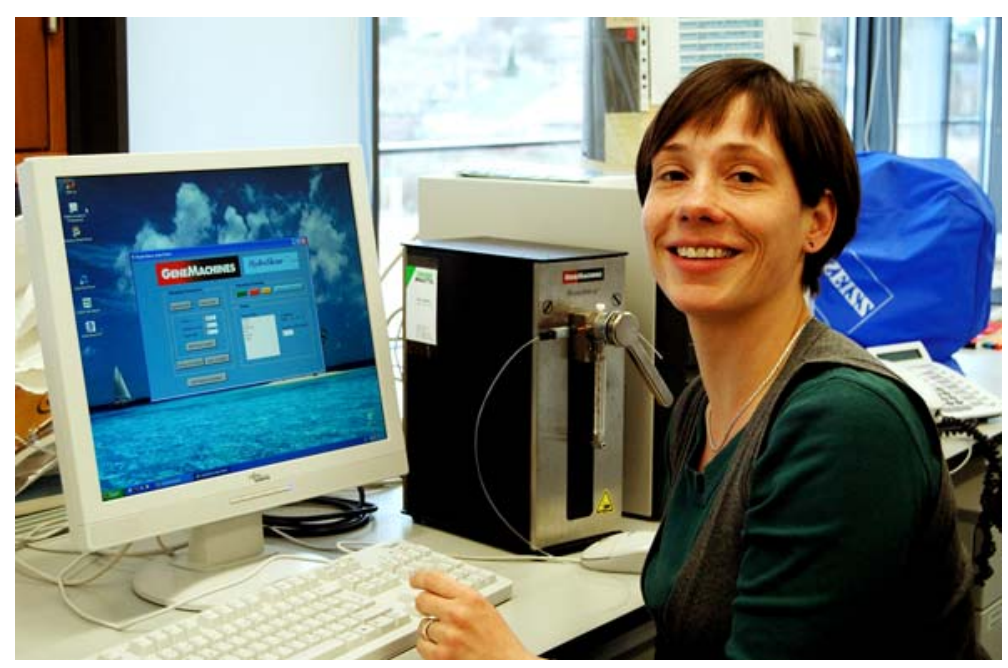

